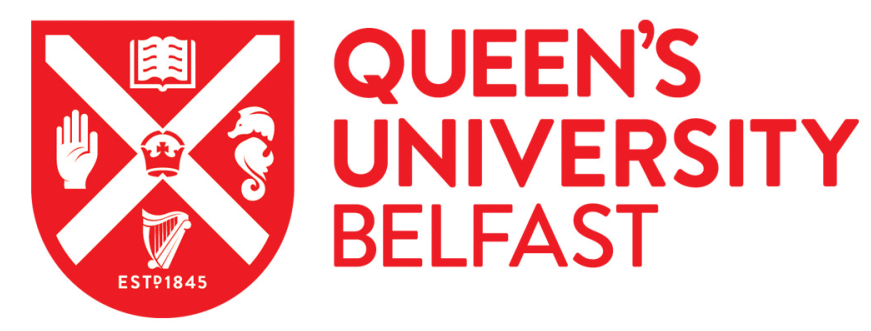

\title{
Overestimated crash risks of young and elderly drivers
}

Rolison, J. J., Moutari, S., Hewson, P. J., \& Hellier, E. (2014). Overestimated crash risks of young and elderly drivers. American Journal of Preventive Medicine, 46(1), 58-64. https://doi.org/10.1016/j.amepre.2013.08.014

\section{Published in:}

American Journal of Preventive Medicine

\section{Document Version:}

Peer reviewed version

Queen's University Belfast - Research Portal:

Link to publication record in Queen's University Belfast Research Portal

\section{Publisher rights}

(c) 2014 American Journal of Preventive Medicine. Published by Elsevier Inc. This manuscript version is made available under the CC-BYNC-ND 4.0 license http://creativecommons.org/licenses/by-nc-nd/4.0/,which permits distribution and reproduction for non-commercial purposes, provided the author and source are cited.

\section{General rights}

Copyright for the publications made accessible via the Queen's University Belfast Research Portal is retained by the author(s) and / or other copyright owners and it is a condition of accessing these publications that users recognise and abide by the legal requirements associated with these rights.

\section{Take down policy}

The Research Portal is Queen's institutional repository that provides access to Queen's research output. Every effort has been made to ensure that content in the Research Portal does not infringe any person's rights, or applicable UK laws. If you discover content in the Research Portal that you believe breaches copyright or violates any law, please contact openaccess@qub.ac.uk. 


\section{OVERESTIMATED CRASH RISKS OF YOUNG AND ELDERLY DRIVERS}

Jonathan J. Rolison, PhD, Salissou Moutari, PhD, Paul J. Hewson, PhD, Elizabeth Hellier, PhD

Background: Young and elderly drivers are reported to have markedly greater crash rates than drivers of other ages, but they travel less frequently and represent a minority of road users.

Consequently, many crashes involving young or elderly drivers also involve drivers of middle age ranges who travel more frequently.

Purpose: To examine crash rates of young and elderly drivers, controlling for ages of all drivers involved in collisions.

Methods: A retrospective longitudinal study conducted on population-wide two-vehicle crashes reported in Great Britain from 2002 through 2010 for driver age ranges (17-20, 21-29, 30-39, 40-49, 50-59, 60-69, 70+ years) and individual driver ages among those aged 17-20 years. Annual trips made, recorded as part of a National Travel Survey, were used to estimate tripbased driver crash rates.

Results: Crash rates of drivers aged 17-20 years were not significantly different from crash rates of drivers aged $21-29$ years (rate ratio $=1.14 ; 95 \% \mathrm{CI}=0.96,1.33$ ) when controlling for ages of both drivers involved in two-car collisions, and drivers aged 17 years had the lowest crash rate among drivers aged 17-20 years. Crash rates of drivers aged 70+ years equaled crash rates of drivers aged $60-69$ years (rate ratio $=1.00 ; 95 \% \mathrm{CI}=0.77,1.32)$ and were 1.40 times $(95 \%$ $\mathrm{CI}=1.10,1.78)$ lower than crash rates of drivers aged $50-59$ years.

Conclusions: The current findings are in contrast with reports of high crash risks among young and elderly drivers, and suggest that previous reports may have overestimated the crash risks of these drivers by failing to control for ages of all drivers involved in collisions. 
INTRODCUTION

30 In 2010, 1.24 million deaths worldwide were the result of motor vehicle crashes. ${ }^{1}$ The World

31 Health Organization warns that if current trends continue, road traffic fatalities will become the

32 fifth leading cause of death by $2030 .{ }^{1}$ Central to concerns for road safety are younger and older

33 drivers who are reported to have markedly greater crash rates per mile driven or per trip made

34 than drivers of other ages. ${ }^{2-5}$ Teenage drivers are reported to have fatal crash rates that are as

35 much as 7 times the rate of drivers aged 30-59 years, ${ }^{2,3}$ and drivers aged $70+$ are reported to

36 have fatal crash rates in excess of 4 times those of drivers in middle age ranges. ${ }^{5}$ Policymakers

37 have responded by proposing graduated licensing systems for teenagers to foster the

38 development of driver experience in low-risk driving conditions. ${ }^{6,7}$ License renewal regulations

39 have been enforced for older adults in response to reports of high crash rates among elderly

40 drivers, ${ }^{8}$ and health care professionals are increasingly being called to assess the driving abilities

41 of older adults. ${ }^{9}$

42 The majority of crashes that result in driver or passenger injury involve 2 vehicles. A

43

44

total of 91,870 crashes in Great Britain in 2010 were between 2 vehicles, compared with 23,824 crashes involving a single vehicle and 27,460 crashes involving 3 or more vehicles. ${ }^{10}$ Younger and older drivers travel less frequently than drivers of other age ranges and represent a small proportion of road users. ${ }^{11}$ Drivers aged 17-20 years made 654 million trips in Britain in 2010 and drivers aged $70+$ years made 2.12 billion trips in the same period, compared with $2.81,4.72$, $6.22,3.21$, and 4.66 billion trips made by drivers aged $21-29,30-39,40-49,50-59$, and 60-69 years, respectively. ${ }^{11}$ Thus, many crashes that involve younger and older drivers involve drivers 
50 of other age ranges who travel more frequently. Crash rates by driver age control for risk

51 exposure (e.g., trips made) but do not control for the travel of other drivers involved in the same

52 collision. We hypothesized that previous reports have overestimated crash rates of young and

53 elderly drivers and underestimated crash rates of drivers of the middle age ranges by failing to

54 control for ages of all drivers involved in multiple-car collisions.

\section{METHODS}

\section{Data Sources}

57 For the current study we used population-wide motor vehicle crashes involving 2 vehicles

58 recorded in Great Britain (England, Scotland, and Wales) from years 2002 through 2010,

59 provided by the University of Essex Data Archive. The data were collected on location by police

60 officials and include collisions involving one or more casualties. Casualties could include

61 drivers, passengers, or pedestrians. The collision data were processed by the UK Department of

62 Transport (DoT) before being made available for public consumption. ${ }^{10}$ Estimated annual trip

63 numbers by gender, driver age range (17-20, 21-29, 30-39, 40-49, 50-59, 60-69, 70+ years)

64 and for individual driver ages $(17,18,19,20$ years) within the 17- to 20 -year age range were

65 used to measure driver exposure, provided by the UK DoT. The trip data were collected as part

66 of the UK National Travel Survey for which approximately 20,000 respondents complete a 7-day

67 travel diary to record their personal travel patterns. ${ }^{11}$ An invitation letter to participate in the

68 survey is sent to a random sample of individuals based on their postcode address. A member of

69 the UK National Travel Survey then personally delivers a travel diary to each respondent's home

70 and collects and checks the completed travel diary of each respondent. The annual response rate

71 ranges between $55-60 \%{ }^{12}$ Short journeys less than $1 \mathrm{~km}$ in length are excluded from the data

72 prior to being made available for public consumption. 


\section{Statistical Analysis}

\section{$74 \quad$ Trip-based crash rates}

75 We conducted generalized Poisson log-linear regression modeling on crash counts involving 2 76 vehicles. In our analysis of driver age ranges, age (17-20, 21-29, 30-39, 40-49, 50-59, 60-69,

77 70+ years) was included as a factor, with year (2002-2010) as a covariate. Annual number of 78 trips made by drivers of each age range was included as an offset term to control for driver 79 exposure by age and to calculate trip-based crash rates. Thus, trip-based crash rates for each 80 driver age, $\mathrm{Age}_{i}$, equaled total crashes by trips made, such that

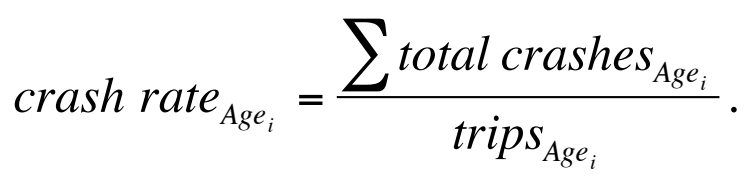

82 We assessed driver crash rates also for individual ages within the 17 - to 20 -year age range. For

83 this analysis, driver age was categorized as 17, 18, 19, or 20 years and was included as a factor, with year (2002-2010) as a covariate. Annual number of trips made by drivers of each individual

85 age was included as the offset term to calculate trip-based crash rates for each driver age. We also assessed driver crash rates for men and women aged 17 years and older by including gender as a factor, year (2002-2010) as a covariate, and annual number of trips made by men and women aged 17 years and older as the offset term.

Crash rates by driver age control for trips made but do not control for trips made by other drivers involved in the same collisions. We controlled for exposure by age of both drivers involved in collisions in our assessment of adjusted crash rates. In our log-linear regression model, crash counts were included by age of both drivers involved in collisions. Driver exposure by age of both drivers was calculated by computing the square root of the product of annual trips made by both driver ages involved in collisions. This was done to adjust for trips made by both 
drivers and was included as an offset term to measure trip-based crash rates. This meant that the age range factor $(17-20,21-29,30-39,40-49,50-59,60-69,70+$ years $)$ represented the tripbased crash rates of each driver age range after adjusting for exposure of both drivers involved in collisions. Thus, adjusted trip-based crash rates for each driver age, $\operatorname{Age}_{i}$, equaled the sum of crash counts involving each other driver age, Age ${ }_{j}$, divided by the square root of the product of trips made by both driver ages:

$$
\text { adjusted crash rate }_{\mathrm{Age}_{i}}=\sum_{\mathrm{Age}_{j}=1}^{n} \frac{\text { crashes }_{\mathrm{Age}_{i} \mathrm{Age}_{j}}}{\sqrt{\operatorname{trips}_{\mathrm{Age}_{i}} \times \text { trips }_{\mathrm{Age}_{j}}}} .
$$

In our assessment of adjusted crash rates of individual ages within the 17- to 20-year age range, crash counts by age of both drivers involved in collisions were included. Driver age was categorized as 17, 18, 19, or 20 years. For collisions in which the other driver involved in the collision was older than 20 years of age, age was categorized as $21-29,30-39,40-49,50-59$, 60-69, and 70+ years. Driver exposure, calculated as the square root of the product of annual trips made by both driver ages, was included as the offset term. Thus, adjusted crash rates for 17, 18-, 19-, and 20-year-old drivers were assessed after controlling for ages of both drivers involved in collisions. In our assessment of adjusted crash rates of men and women, crash counts were included by gender of both drivers involved in collisions and driver exposure was the square root of the product of annual trips made by both driver genders.

\section{Population-based crash count estimates}

Reported crash counts in the population from years 2003 through 2010 were compared with crash counts estimated by crash rates of the period starting and ending one year earlier (2002 to 2009). Annual trip data for each driver age were substituted for each year in the crash rates of the previous year to estimate crash counts for the following year. Prediction error was defined as the 
117 absolute difference between reported and estimated crash counts as a proportion of reported 118 crash counts.

\section{RESULTS}

120

121

122

123

124 125

126

127

128

129

130

131

132

133

134

135

136

137

138

139

9

\section{Trip-Based Crash Rates}

Drivers aged 17-20 years had a crash rate that was 2.33 (95\% CI, 2.22-2.44), 4.55 (95\% CI, 4.35-4.55), and 5.88 (95\% CI, 5.88-6.25) times greater than that of drivers aged 21-29, 30-39, and 40-49 years, respectively (Figure 1A; Table 1). The adjusted crash rate of drivers aged 1720 was 1.14 (95\% CI, 0.96-1.33), 1.56 (95\% CI, 1.32-1.85), and 2.00 (95\% CI, 1.69-2.38) times greater than that of drivers aged 21-29, 30-39, and 40-49 years, respectively (Figure 1A; Table 1). Thus, the adjusted crash rate of drivers aged 17-20 years was lower after controlling for age of both drivers involved in collisions and was not significantly different from the adjusted crash rate of drivers aged $21-29$ years.

30

31

$$
\text { CI, 1.08-1.19) times greater than that of drivers aged 60-69 and 50-59 years, respectively }
$$

(Figure 1A; Table 1). The adjusted crash rate of drivers aged $70+$ years equaled the adjusted crash rate of drivers aged 60-69 years (rate ratio=1.00; 95\% CI, 0.77-1.32) and was 1.40 times (95\% CI, 1.10-1.78) lower than the adjusted crash rate of drivers aged 50-59 years (Figure 1A; Table 1). Thus, adjusted crash rates were not greater for older (i.e., 70+) adult drivers than for other age ranges after controlling for age of both drivers involved in collisions.

Drivers aged 17 years had a crash rate that was 1.18 (95\% CI, 1.02-1.33), 1.32 (95\% CI, 1.15-1.50), and 1.35 (95\% CI, 1.19-1.54) times greater than that of drivers aged 18, 19, and 20 years, respectively (Figure 1B; Table 1). The adjusted crash rate of drivers aged 17 years was 
140 instead 1.31 (95\% CI, 1.44-1.50), 1.21 (95\% CI, 1.05-1.39), and 1.21 (95\% CI, 1.05-1.38) times

141 lower than the adjusted crash rates of drivers aged 18, 19, and 20 years, such that drivers aged 17

142 years had the lowest crash rate among 17- to 20-year-olds after controlling for age of both

143 drivers involved in collisions (Figure 1B; Table 1).

144 The crash rate of male drivers was 1.12 (95\% CI, 1.10-1.15) times greater than for

145 women (Table 1), and the adjusted crash rate of male drivers was 1.25 (95\% CI, 1.01-1.56) times

146 greater than for women. Thus, the adjusted crash rate of male drivers with respect to female

147 drivers was greater after controlling for both driver genders involved in collisions as women

148 overall made fewer trips than men (Table 1).

149 Population-Based Crash Count Estimates

150 Population-based crash count estimates for age ranges were more accurate overall when based on 151 adjusted crash rates of the previous year (Figure 2A). Figure $2 \mathrm{~B}$ shows that the prediction error

152 for estimated crash counts was smaller for all age ranges (except drivers aged 30-39 years) when

153 based on adjusted crash rates that controlled for ages of both drivers involved in collisions.

154 Reductions in prediction error were largest for the youngest (17-20 years) and oldest (70+ years)

155 drivers (Figure 2B). Regarding individual ages, crash count estimates were more accurate for 17-

156 , 18-, 19-, and 20-year-old drivers when based on adjusted crash rates of the previous year

157 (Figure 3A) and prediction error was also reduced for each driver age when based on adjusted

158 crash rates (Figure 3B). Thus, adjusted crash rates for age ranges and individual ages were more

159 accurate as a result of controlling for ages of both drivers involved in collisions.

\section{DISCUSSION}

161 Young and elderly drivers travel less frequently than people in other age ranges and represent a

162 minority of road users. ${ }^{11}$ Many crashes that involve younger and older drivers as a result involve 
163 drivers of middle age ranges who travel more frequently. Crash rates control for driver exposure 164 by age but do not control for the travel of other drivers involved in the same collision. Our 165 analysis suggests that previous reports may have overestimated crash rates of young and elderly 166 drivers and underestimated crash rates of drivers in middle age ranges by failing to account for 167 ages of all drivers involved in multiple-car collisions (Figure 1). Furthermore, estimates of crash 168 counts in the population were more accurate when based on adjusted crash rates of the previous 169 year that controlled for ages of all drivers involved in collisions (Figures 2 and 3).

Policymakers around the world have responded to reports of high crash rates among

171 young drivers by recommending graduated licensing systems and educational interventions for 172 teenagers to encourage the development of driver skill. ${ }^{6,7}$ Our study shows that crash rates of 173 young drivers may have been overestimated in previous reports. Adjusted crash rates of drivers 174 aged 17-20 years did not differ significantly from the adjusted crash rate of drivers aged 21-29 175 years (Figure 1A) and were lowest for 17-year-olds among drivers aged 17-20 years (Figure 176 1B). In Great Britain, youngest drivers are charged a high premium according to the engine 177 capacity of their vehicle, which restricts youngest drivers to lower performance cars. ${ }^{13}$ Crash 178 risks are linked to driving speed, ${ }^{14}$ suggesting that insurance restrictions may reduce crash risks 179 among youngest drivers. Adjusted crash rates reduced smoothly across age ranges (Figure 1A), 180 indicating that driver skill may develop more gradually than currently believed. We recommend 181 that in addition to promoting policies that target young drivers, policymakers should consider the 182 benefits of prolonged driver training initiatives, such as advanced driver training courses and 183 further driver assessments for developing driver skill. License renewal regulations for older adults have been tightened by policymakers in 185 response to reports of high crash rates among elderly drivers. ${ }^{8}$ The American Medical 
Association now encourages physicians to screen older adults for cognitive and visual impairment that might affect driver safety, ${ }^{15}$ charging medical practitioners with difficult decisions about the driving privileges of older adults. ${ }^{9}$ Age-based testing discourages unimpaired elderly drivers from renewing their driver license, ${ }^{16}$ which compromises mobility with direct effects on well-being and multiple health outcomes. ${ }^{17}$ Our results show that adjusted crash rates were not greater for elderly drivers, which signifies that the strong emphasis on license renewal regulations and screening of older adults may be misplaced. Adjusted crash rates for drivers aged $70+$ years equaled those of drivers aged 60-69 years and were lower than the adjusted crash rates of drivers aged 50-59 years (Figure 1A).

In Great Britain, $83 \%$ of car crashes in 2010 involved 2 or more vehicles. ${ }^{10}$ Failure to control for ages of all drivers involved in collisions in previous studies may have biased estimates of driver crash rates. Biases in crash rate estimates can occur whenever drivers involved in multiple car collisions differ in their travel patterns. Women make fewer trips than men each year as drivers, and as a result we found that the crash rate of female drivers was lower with respect to male drivers after controlling for both driver genders involved in collisions.

The present study has a number of limitations. First, our measures of exposure were based on annual trips made by drivers and controlled for neither the length of journey nor the nature of trips made (e.g., leisure, work commute), for which there may be systematic differences with age. Second, in our analysis of 2 vehicle collisions we did not account for which driver was most likely at fault. Skill level, inexperience, and risk taking behaviors are associated with increased crash risks among younger drivers, ${ }^{3,4}$ and cognitive limitations and visual impairment have been linked to driver error in older age. ${ }^{18}$ Age differences in the degree to which drivers are the cause of their collisions may have affected our age comparisons. Third, the 
209 reliability of crash data used in our study depend on crashes being accurately reported by police

210 officials, and the reliability of our exposure data depend on respondents to a national travel

211 survey accurately recording their personal travel patterns. Any inaccuracies in our data, however,

212 should not have differed systematically with age or gender of the driver, and thus should not

213 have affected our main findings. The data used in our current analysis represents the most

214 accurate road safety data available in Great Britain.

215 Our current findings suggest that previous reports may have overestimated the crash rates

216 of young and elderly drivers by failing to account for ages of all drivers involved in multiple-car

217 collisions. We focused our current investigation on 2 vehicle crashes in Great Britain over a 9

218 year period (years 2002-2010). Before strong claims can be made about the generality and

219 robustness of our findings, further investigations are needed to assess adjusted crash rates in

220 other countries that adopt different road safety policies. We currently investigated all 2 vehicle

221 crashes involving at least one casualty. It is important to further demonstrate that our findings

222 can be replicated for both fatal and non-fatal driver casualties.

The World Health Organization reported that 1.24 million deaths worldwide in 2010

224 were the result of motor vehicle crashes and warns that road traffic injuries will become the fifth

225 leading cause of death by $2030 .{ }^{1} \mathrm{We}$ recommend that policymakers consider prolonged training

226 programs and assessment initiatives in addition to policies targeting young drivers. We urge

227 policymakers to focus public health initiatives on safeguarding all road users, noting that elderly

228 pedestrians represent the majority of road traffic deaths. ${ }^{5}$ 


\section{REFERENCE LIST}

235 1. World Health Organization. Global Status Report on Road Safety: 2013 [on-line].

236 http://www.who.int/violence injury prevention/road safety status/2013/report/en/index.html

$237 \quad$ Accessed March 26, 2013.

238 2. Williams AF. Teenage drivers: patterns of risk. J Safety Res. 2003;34:5-15.

239 3. Rolison JJ, Hewson PJ, Hellier E, Hurst L. Risks of high-powered motorcycles among $240 \quad$ younger adults. Am J Public Health 2013;103:568-571

241 4. Shope JT, Bingham CR. Teenage driving: Motor-vehicle crashes and factors that contribute.

$242 \quad$ Am J Prev Med. 2008;35:261-271.

243 5. Rolison JJ, Hewson PJ, Hellier E, Husband P. Risk of fatal injury in older adult drivers, 244 passengers, and pedestrians. J Am Geriatr Soc. 2012;60:1504-1508.

245 6. Chen L-H, Baker SP, Guohua L. Graduated driver licensing programs and fatal crashes of 16246 year-old drivers: a national evaluation. Pediatrics. 2006;118:56-62.

247 7. Masten SV, Foss RD, Marshall SW. Graduated driver licensing and fatal crashes involving 248 16- to 19-year-old drivers. JAMA. 2011;306:1098-1103.

249 8. Grabowski DC, Campbell CM, Morrisey MA. Elderly license laws and motor vehicle 250 fatalities. JAMA. 2004;291:2840-2846.

251 9. Carr DB, Ott BR. The older driver with cognitive impairment: it's a frustrating life. JAMA. $252 \quad 2010 ; 303: 1632-1641$. 
253 10. Department for Transport. Reported Road Casualties Great Britain: 2010 [on-line].

$254 \quad$ http://assets.dft.gov.uk/statistics/releases/road-accidents-and-safety-annual-report-

$255 \quad$ 2010/rrcgb2010-complete.pdf. Accessed March 26, 2013.

256 11. Department for Transport. National Travel Survey: 2010 [on-line].

257 https:/www.gov.uk/government/uploads/system/uploads/attachment data/file/8932/nts2010-

$258 \quad$ 01.pdf. Accessed March 26, 2013.

259 12. Department for Transport. National Travel Survey 2010: Technical Report [on-line].

260 http://assets.dft.gov.uk/statistics/series/national-travel-survey/nts2010-technical.pdf. Accessed

$261 \quad$ March 26, 2013.

262 13. The AA. Car insurance groups. [on-line]. http://www.theaa.com/insurance/car-insurance-

263 groups.html. Accessed March 26, 2013.

264 14. Aarsts L, van Schagen I. Driving speed and the risk of road crashes: A review. Accid Anal

265 Prev 2006; 38:215-224.

266 15. Physician's Guide to Assessing and Counseling Older Drivers, 3rd edition. American Medical

267 Association; 2010.

268 16. Ross LA, Browning C, Luszcz MA, et al. Age-based testing for driver's license renewal:

269 potential implications for older Australians. J Am Geriatr Soc. 2011;59:281-285.

270 17. Oxley J, Whelan M. It cannot be all about safety: the benefits of prolonged mobility. Traffic

$271 \quad$ Inj Prev. 2008;9:367-378.

272 18. Anstey KJ, Wood J, Lord S et al. Cognitive, sensory, and physical factors enabling driving

273 safety in older adults. Clin Psychol Rev 2005;25:45-65

274

275 
Table 1. Trip-Based Relative Risk for Crashes by Driver Age in Great Britain, 2002-2010.

\begin{tabular}{lcccccc}
\hline Variable & $\begin{array}{c}\text { Crash } \\
\text { Counts }\end{array}$ & $\begin{array}{c}\text { Trips, } \times 10 \\
\text { Million }\end{array}$ & Crash Rate & $\begin{array}{c}\text { Adjusted } \\
\text { Crash Rate }\end{array}$ & $\begin{array}{c}\text { Relative Risk } \\
\text { Crash Rate }\end{array}$ & $\begin{array}{c}\text { Relative Risk } \\
\text { Adjusted } \\
\text { Crash Rate }\end{array}$ \\
\hline 17-20 years & 10322 & 67.48 & 157.06 & 71.81 & 1.00 & 1.00 \\
$21-29$ years & 18827 & 284.93 & 67.47 & 63.56 & $0.43(0.41-0.45)$ & $0.88(0.75-1.04)$ \\
30-39 years & 19002 & 544.17 & 35.22 & 46.16 & $0.22(0.22-0.23)$ & $0.64(0.54-0.76)$ \\
$40-49$ years & 15584 & 610.91 & 26.07 & 35.95 & $0.17(0.16-0.17)$ & $0.50(0.42-0.59)$ \\
$50-59$ years & 10310 & 467.93 & 22.44 & 27.11 & $0.14(0.14-0.15)$ & $0.38(0.31-0.46)$ \\
$60-69$ years & 5775 & 292.83 & 20.28 & 19.32 & $0.13(0.12-0.14)$ & $0.27(0.22-0.34)$ \\
$70+$ years & 4622 & 187.27 & 25.45 & 19.36 & $0.16(0.15-0.17)$ & $0.27(0.21-0.34)$ \\
& & & & & & \\
17 years & 1563 & 8.07 & 195.75 & 16.66 & 1.00 & 1.00 \\
18 years & 3162 & 18.99 & 167.31 & 21.86 & $0.85(0.75-0.98)$ & $1.31(1.44-1.50)$ \\
19 years & 2999 & 20.61 & 148.83 & 20.10 & $0.76(0.67-0.87)$ & $1.21(1.05-1.39)$ \\
20 years & 3088 & 21.64 & 144.30 & 10.99 & $0.74(0.65-0.84)$ & $1.21(1.05-1.38)$ \\
& & & & & & 1.00 \\
Women & 28181 & 1096.66 & 25.71 & 24.36 & & 1.00 \\
Men & 39358 & 1357.04 & 28.87 & 30.51 & $1.12(1.10-1.15)$ & $1.25(1.01-1.56)$ \\
Overall & 46531 & 2455.51 & 18.95 & & & \\
\hline
\end{tabular}

279 Note. Crash counts and estimated trip numbers are average annual figures from 2002 through 2010 280 for Great Britain supplied by the UK Department of Transport. Crash counts are population-wide 281 motor vehicle crashes involving 2 vehicles and represent the total number of crashes involving a 282 driver of each age range (21-29, 30-39, 40-49, 50-59, 60-69, and 70+ years), individual age (17, 28318,19 , and 20 years), and gender. Stratifying 2 vehicle-crashes (e.g., by age or gender) results in 284 some double counting of collisions. For example, a single crash involving a 17 year old driver and 285 an 18 year old driver is counted both in the crash counts of 17 year olds and in the crash counts of 28618 year olds. This causes total crash counts across subgroups to vary according to the number 287 stratified subgroups. Estimated trip numbers were collected as part of the UK National Travel 288 Survey. Crash rates for each driver age (or gender) control for number of trips made; adjusted 289 crash rates for each driver age (or gender) control for number of trips made by both drivers 290 involved in collisions. All crash rates and adjusted crash rates were estimated from our regression 291 analyses, except the overall crash rate estimate. Trip numbers are Figures in parenthesis for 
292 relative risks indicate 95\% confidence intervals. Relative risks for drivers aged 17-20 years and 293 drivers aged 17 years are the reference groups.

294 